\title{
Granulometric composition study of mineral resources using opto-electronic devices and Elsieve software system
}

\author{
Stanislaw Kaminski ${ }^{1}$, Piotr Kaminski ${ }^{1}$, Dorota Kaminska ${ }^{1}$, and Jerzy Trzcinski ${ }^{2, a}$ \\ ${ }^{1}$ Kamika Instruments, Strawczyńska 16, 01-473 Warsaw, Poland \\ ${ }^{2}$ Faculty of Geology, University of Warsaw, Żwirki i Wigury 93, 02-089 Warsaw, Poland
}

\begin{abstract}
The use of mechanical sieves has a great impact on measurement results because occurrence of anisometric particles causes undercounting the average size. Such errors can be avoided by using opto-electronic measuring devices that enable measurement of particles from $10 \mu \mathrm{m}$ up to a few dozen millimetres in size. The results of measurement of each particle size fraction are summed up proportionally to its weight with the use of Elsieve software system and for every type of material particle-size distribution can be obtained. The software allows further statistical interpretation of the results. Beam of infrared radiation identifies size of particles and counts them precisely. Every particle is represented by an electronic impulse proportional to its size. Measurement of particles in aqueous suspension that replaces the hydrometer method can be carried out by using the IPS L analyser (range from 0.2 to $600 \mu \mathrm{m}$ ). The IPS UA analyser (range from 0.5 to $2000 \mu \mathrm{m}$ ) is designed for measurement in the air. An ultrasonic adapter enables performing measurements of moist and aggregated particles from 0.5 to $1000 \mu \mathrm{m}$. The construction and software system allow to determine second dimension of the particle, its shape coefficient and specific surface area. The AWK 3D analyser (range from 0.2 to $31.5 \mathrm{~mm}$ ) is devoted to measurement of various powdery materials with subsequent determination of particle shape. The AWK B analyser (range from 1 to $130 \mathrm{~mm}$ ) measures materials of thick granulation and shape of the grains. The presented method of measurement repeatedly accelerates and facilitates study of granulometric composition.
\end{abstract}

\section{Introduction}

Measurement using mechanical sieves takes into account the smallest dimension of the particle that has to be inscribed in a square, whose side equals the dimension of sieve mesh. The size of the square sieve mesh is assumed to be the size of the particle. Usually, particles are not spherical. For example elliptical particles are measured on sieves according to the smallest dimension of the ellipse. During sieve measurement, particles are weighted correctly, but measurement of their size is prone to errors. The use of the set of sieves with diverse strength and method of shaking and different time of operation can also have strong influence on the results. Particles of longitudinal shape cause undercounting during determination based on medium sized sieves. Those errors can be avoided by using opto-electronic measuring devices.

${ }^{\text {a }}$ Corresponding author: jt@kamika.pl 
Addressing this problem generates basic question: is it possible to precisely measure particle size distribution of the material that consists of the particles of various sizes ranging from a few $\mu \mathrm{m}$ to tens of $\mathrm{mm}$ ? A set of elements of such material is numerically large, and construction of a single measuring device does not allow to measure spectrum of particle sizes this wide. The solution can be to use a system that would consist of a few opto-electronic devices. Each of them would perform independent measurement for the precisely set size range of grains diameters. The particle size distribution would be summed up proportionally to the weight particle size fraction of each range.

\section{Principle of measurement}

Let us consider how to measure grain size distribution of material consisting of particles from $10 \mu \mathrm{m}$ to fragments with maximum dimension up to several dozens of $\mathrm{mm}$. Counting by a volume ratio, quantity of smaller particles equivalent to one big fragment is really large. The set of particles is so numerically large that no single device can measure it in the considerable amount of time. This task can be facilitated by a specified method of measurement.

A sample is divided into a few parts (fraction ranges) by being transferred through the sieves. Each fraction is weighted and representative samples for the measurement with opto-electronic devices are prepared. The representative sample for the grain size fraction of fine particles below $1 \mathrm{~mm}$ is usually a small part of the whole set and consists of many millions of particles. A medium grain size fraction (from 1 to $10 \mathrm{~mm}$ ) is represented by tens of thousands of particles. The particle size fraction of thick particles (larger than $10 \mathrm{~mm}$ ) usually consists of a few thousands of particles and can be measured as a whole. Results of measurement of every grain size fraction are summed up proportionally to their weight with the use of opto-electronic Elsieve method and distribution of volume simulates sedimentary and sieve analysis. The particle size distribution is constructed proportionally to the weight share of divided particle size fraction groups.

Measuring system can consist of any number of devices connected individually to steering and registering computer. A computer of each measuring device is connected to a central computer acting as a server. The software of the measuring system provides access to the results saved on the server. They can be summed up on any computer connected to this network. The presented method significantly accelerates and facilitates study of granulometric composition.

Any system of opto-electronic devices can be used to calculate results of analysis and to obtain the particle-size distribution for all materials. If the user is missing one of the devices, its work can be replaced with traditional sieve method and results (sieve's size and weight of the material on the sieve) can be entered directly into the software.

The presented method of measurement significantly accelerates and facilitates obtaining the particle size distribution curve and automatically determines compatibility of the material with various norms, for example PN-ISO 565: 2000, PN-B-04481: 1988, and PN-EN ISO 14688-2: 2006.

The system of this type is currently used to measure granulometric composition of soils, rocks and various geo materials in the laboratory of Institute of Hydrogeology and Engineering Geology, Faculty of Geology, University of Warsaw [1, 2, 3, 5].

\section{Measurement method}

The method of measurement by opto-electronic devices relies on determining the size of the smallest particles in order to gradually, in a steady manner, switch to the measurement of changes in the beam or radiation scattered by moving larger particles. There are no optical limits for measurement of single fine and thick particles in the analysers. The beam of infrared radiation not only identifies the particle size, but also allows to precisely count particles in the whole measurement range. Every particle is represented by an electric impulse proportional to its size. A set of particles is primarily measured with the division into 4096 size fractions and transformed (calibrated) into 256 size fractions. 
Apart from the software designed for the measurement of particles, analysers are also equipped with a software for optimization of any parameter as a function of granulometric composition of the measured suspension or powder. There is also a software for calculating the grain size distribution by any calibration (for sieve method, hydrometer method or spherical). The measurement results are presented in either colourful diagrams or tables.

\section{Selected types of opto-electronic analysers}

\subsection{IPS $L$ analyser - measurement range 0.2 - $600 \mu \mathrm{m}$}

The analyser is designed for the measurement of particle size distribution in aqueous suspension irrespective of their chemical and physical properties. Solid and oily particles as well as air bubbles can be measured. It completely substitutes hydrometer method.

\subsubsection{Method of measurement}

Water or aqueous solutions with suspended particles is introduced from a container, equipped with a mixer, into water passing through the analyser. Flow of water is automatically regulated by switching on a feeding pomp. Measurement of particles size is completely automatic and regulated by a computer. Filter cleans water from the particles. Operation and permeability of the filter is controlled with a manometer. Clean water transported to a chamber flows into the measurement zone, where a needle dosing water with suspended particles is located. Clean water prevents optics in the sensor from getting dirty. Feeding the pomp, that is placed after the sensor, additionally sucks water and is regulated via the computer.

\subsection{IPS UA analyser - measurement range 0.5 - $2000 \mu \mathrm{m}$}

The analyser is designer for the measurement of solid particles size distribution in the air irrespective of their physical and chemical properties under laboratory conditions. With addition of ultrasonic adapter, the analyser can be used to measure the size of moist and aggregated particles (size range from 0.5 to $1000 \mu \mathrm{m}$ ). Construction of the analyser and applied software enable determining second dimension of particle, its coefficient of shape and specific surface area (when the coefficient of intraparticle porosity is known).

\subsubsection{Method of measurement}

The analyser consists of a measuring sensor and a measuring system integrated with the electronic system that is feeding the particles, providing continuity of the measurement and control of concentration of the particles in the measurement zone. The entire process is regulated by a computer equipped with the technical software system. A small compressor is the executive element of the automatic feeding system. The compressor has specific characteristics, adjusted to stable regulation of the air flow.

An ultrasonic feeder is used to separate 'glued' particles. The feeder has a shape of a concave vessel. Its bottom vibrates with the frequency of $40 \mathrm{kHz}$ and with the amplitude up to a few $\mathrm{mm}$. The moist substance is dried due to vibrations. Even significant humidity of the sample does not disturb the measurement. For feeding various granular materials, regulation of the amplitude and quantity of ultrasonic impulses has around 4000 transitional states between 0 and the maximum operational level of the feeder. Control over the airflow transmitting previously separated particles into measurement zone provides precision of feeding. Regulation of the airflow has around 300 levels of speed. Such a 
precise control of the feeder enables measuring single particles quickly (up to several thousand particles per second) and avoiding coincidence of particles in the measurement zone.

\subsection{AWK 3D analyser - measurement range $0.2-31.5 \mathrm{~mm}$}

The analyser is destined for the measurement of powdery materials like raw materials (fine aggregates, gravel, coarse sands), coal, plant seeds, food granulates and plastics under laboratory conditions. A software system used to operate this device enables full simulation of the measurement on mechanical sieves. The device can be used during either production or technological processes during optimization of milling and selection of compound of various materials. Additional useful function is the ability to determine the shape of the particle.

\subsubsection{Method of measurement}

The AWK 3D analyser is equipped with an electronic measuring block, connected with two independent optical tracks to determine the particles size, all together with counter of measurements, that enables to determine the shape of particles in three dimensions. The electronic measurement block is connected to a computer running analysis and controlling the device. The measurement process is controlled automatically, after the data are entered to the computer through the keyboard. The feeding system consists of the feeder with a vibrating slide. Vibrations are caused by a small electric engine with eccentric load. The engine speed (and vibrations caused by it) is controlled with an electronic system. The range of regulation has 225 levels. If there are too many grains fed to the measurement zone, the speed of the engine slows down and if there are not enough grains falling to the measurement zone, speed of the engine accelerates. Particles are fed to the slide from the charge funnel. Size of the funnel and width of the slide are adjusted accordingly to the size of particles measured. There is a small chimney, located between feeder's slide and measuring sensor, that is supposed to stabilize the fall of particles of different shapes. The feeder transports particles from the funnel to the container placed below the device. When the measurement is finished, feeding is automatically terminated and the results, completely simulating measurements according to mechanical sieves, are processed.

\subsection{AWK B analyser - measurement range $1-130 \mathrm{~mm}$}

The analyser is designed for automatic measurement of either thick aggregates or other materials of similar particle size under laboratory conditions. The device can be constructed to measure in 3 dimensions (3D) and have the same properties as AWK 3D - it can determine the particle shape. The device fully simulates measurements according to mechanical sieves and can be used for the optimization of the production process and for determining the shape of particles.

\subsubsection{Measurement method}

A beam of infrared or laser radiation originating from the sensor is scattered by particles of aggregate flowing through the measurement zone. The measuring system consists of a multi-channel optic system that enables spatial measurement in three directions. Each grain is represented by the corresponding electronic impulse proportional to its size. Set of particles is primarily measured in 4096 size fractions and then transformed (calibrated) into 256 fractions available to the user. A huge measurement surface ' $s$ ' x $300 \mathrm{~mm}$ of identical sensitivity is one of the characteristics of this method. Measurement area dimension ' $s$ ' depends on the type of the applied optics and can be 110, 160 or 190 $\mathrm{mm}$. Additionally, the device is equipped with a special feeder that can fit over a dozen of kilograms of material. 


\subsubsection{Measurement method}

The AWK B analyser is equipped with electronic measurement block connected with electric control box and measuring sensor as well as a desktop computer with a special interface. The whole system is controlled with a computer keyboard. When measurement is terminated, its results are automatically saved by computer memory and analyser settings go back to the initial state. The working section of the analyser is built in the shape of a cart. A steering box equipped with an electric motor operator is suspended on the stainless steel frame. The motor operator, with help of a pusher, inclines the slide hanged on the bearing rod. The measuring sensor with the inlet of $200 \times 300 \mathrm{~mm}$ section is placed on the frame on two supports. The slide is additionally equipped with a vibrator. During the process of measurement, the vibrator gradually reaches maximum vibration, and then the slide is set to the lower position. Through the inlet, the sample slips from the bottom of the slide to right under the analyser. Intensity of the sample slipping is regulated with the use of a computer.

\section{Notes regarding the method}

AWK 3D and AWK B are the analysers constructed for 3-dimensional measurement of particles. The results of measurements of shape are presented according to the Zingg classification [7]. Information determined additionally, considering indicators of particle size distribution calculated on the basis of results of analysis, are: geotechnical name of the soil according to the classification presented in Polish norms PN-B-04481: 1988 and PN-EN ISO 14688-2: 2006, index of heterogeneity particle size distribution, average diameter of grains, standard aberration, skewness and kurtosis. Those information open the door for wider statistical interpretation of the results of granulation studies. It is possible to obtain other characteristics of particle size distribution, depending on what is required by the user .Previously described devices are presented in Fig. 1.

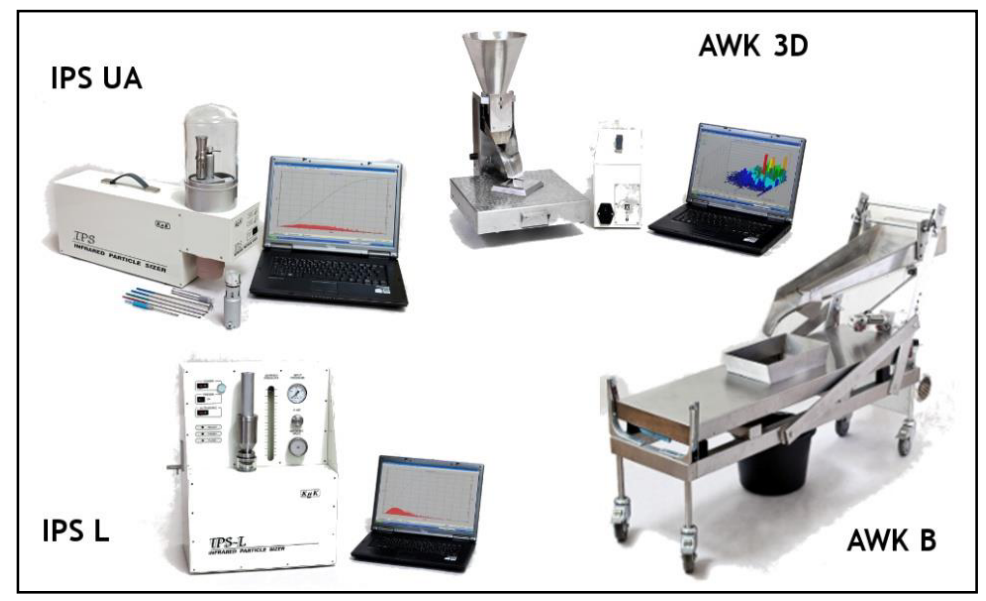

Figure 1. Measuring apparatuses manufactured by KAMIKA Instruments.

\section{Description of the software system}

The software enables user to:

- $\quad$ sum up results of measurements according to sieve calibration performed on different KAMIKA analysers for the measurement of granulometric distribution,

- determine the curve of granulometric distribution in the range from $0.4 \mu \mathrm{m}$ to $30 \mathrm{~mm}$,

- automatically sum up results of measurements carried out on mechanical sieves. 


\subsection{Saving results of sieve analysis}

To start working with the IPSL, IPSU, IPSA, 2DiSA, AWK 3D software system, chosen results of sieve analysis should be saved as SI* files. Different analysers may be used to measure different fractions of geo materials because of their measurement range. Results of the sieve analysis carried out on certain analysers should be saved as different file types, as shown in Table 1.

Table 1. Fractions and types of devices used for their analysis.

\begin{tabular}{|c|c|c|}
\hline Fractions & Analyser & File name with results of sieve analysis \\
\hline Clay & IPS L & $*$.SI1 \\
\hline Silt & IPS U* & ${ }^{*}$.SI2 \\
\hline Sand & IPS A** & ${ }^{*}$.SI3 \\
\hline Gravel & AWK 3D & $*$.SI4 \\
\hline
\end{tabular}

\subsection{Quantity of measurements}

First, the quantity of measurements (fractions) that is supposed to be summed up must be chosen. Results from up to 4 analysers can be summed up (Fig. 2).

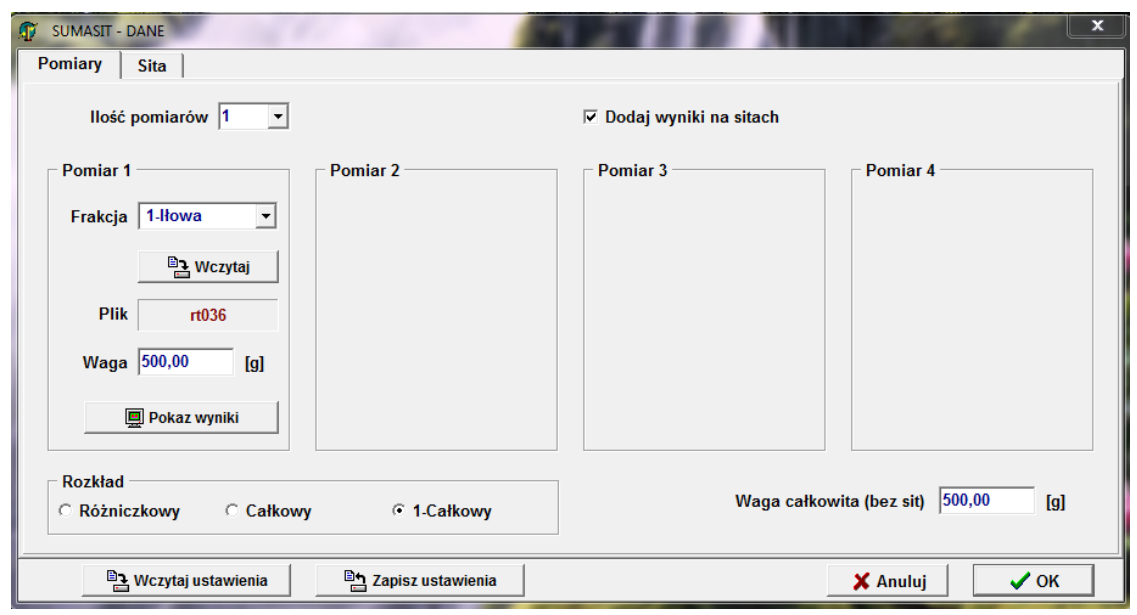

Figure 2. Dialog box for setting number of measurements.

If one measurement is chosen, it can be used for hydrometer analysis, where results from IPS L and measurements on sieves are added. For every result of sieve analysis, that is to be summed up, the type of fraction should be chosen.

\subsection{Weight}

To sum up results of measurements, weights of particular fractions should entered, for respective measurement results in the corresponding fields in the measurement section. Summed weight of fractions should equal to the weight of the whole sample measured with the use of the analyser. If summed weight of fraction is not equal to the weight of the whole sample, information indicating error will appear. 


\subsection{Summing up results from mechanical sieves}

The 'Sum of sieves' software enables to add results from mechanical sieves to the particle size distribution curve. This solution is helpful, when only a part of the sample can be measured with the Kamika analysers, for example when some particles in the sample exceed measurement range of the devices. The result from up to 11 sieves can be added.

It is important for the sieves to be bigger or equal to the biggest sieve in selected results for the biggest fraction and smaller or equal to the smallest sieve in selected results for the smallest fraction. The results from the sieves cannot be added for the ranges between the ranges of the connected devices. The weight on every sieve is automatically included in the calculation of the particle size distribution curve.

\subsection{Results}

The calculated grain size distribution curve is presented in Fig. 3.

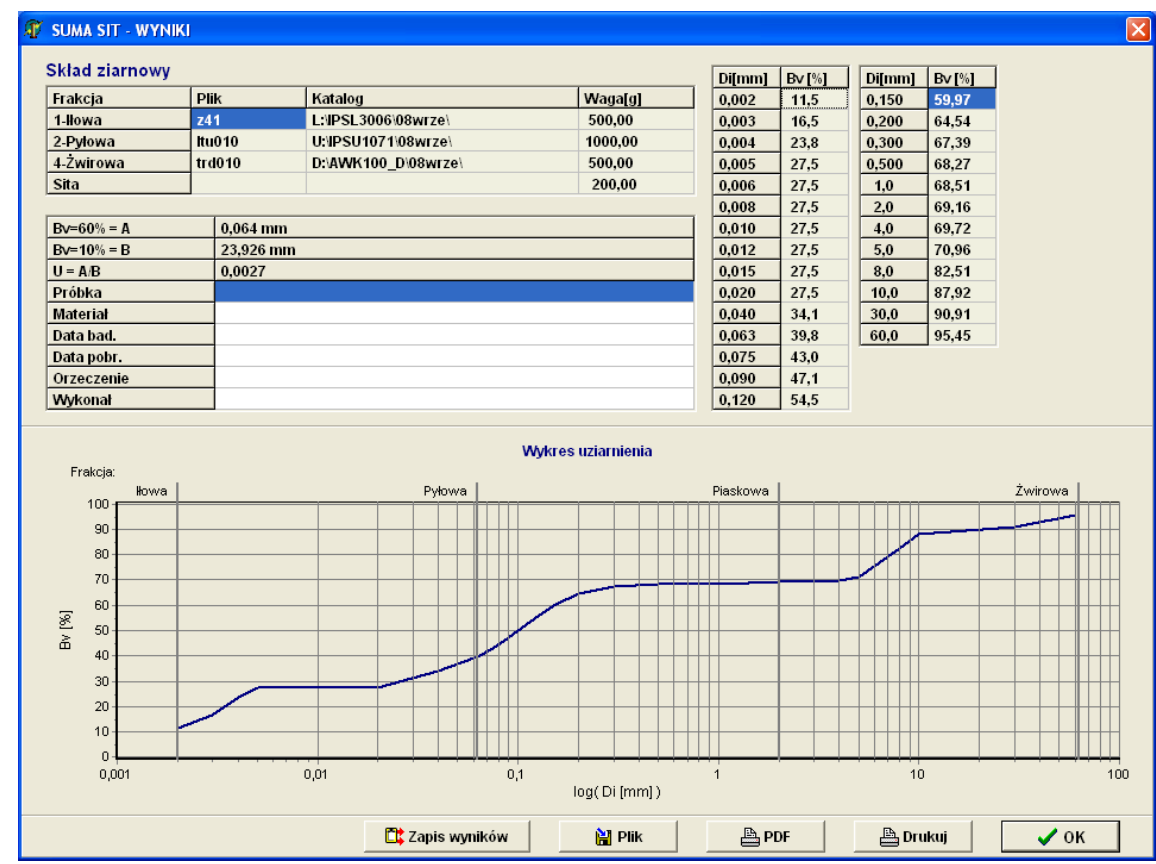

Figure 3. Dialogue box presenting summed results of measurements.

\section{Conclusions}

Using traditional methods of measurement of granulometric composition of various materials is manually challenging and requires a lot of work, both during studies and in practice. Traditional methods of measurement, such as either sieve or sedimentation analyses can cause errors and inaccuracy connected with the method of measurement. Those measurements can be replaced with the $3 \mathrm{D}$ opto-electronic Elsieve analysis of shape and size of particles from $0.5 \mu \mathrm{m}$ to $100 \mathrm{~mm}$ providing also other parameters of the particle size.

When a set of particles is numerically large and varies very much in size, it is not possible to measure it with a single device. This is why the measurement should be performed with a measuring system consisting of a few devices. The whole set should be divided into a few parts (size ranges) and 
representative samples should be prepared. The distribution of grain size is summed up proportionally to weight share of the respective size ranges.

The measuring system consists of a few analysers individually connected with the computer that controls and registers and is conjugated with the server. The software system provides summing up of the measurements on any computer connected to this network. The presented method of measurement accelerates and facilitates studies of granulometric composition.

\section{References}

1. M. Fiolek, MSc thesis (Uniwersytet Warszawski, 2014)

2. T. Gotowiec, MSc thesis (Uniwersytet Warszawski, 2006)

3. K. Jaglinski, MSc thesis (Uniwersytet Warszawski, 2006)

4. S. Kaminski, ELSIEVE Optyczno-elektroniczna symulacja pomiarów mikroziarn powyżej 0,5 $\mu m$ wedtug sit mechanicznych, (2007)

5. S. Kaminski, D. Kaminska, ABiD, 12(2), 85 (2007)

6. P. Malczyk, MSc thesis (Uniwersytet Warszawski, 2015)

7. E. Mycielska-Dowgiallo, in Badania osadów czwartorzedowych. Wybrane metody i interpretacja wynikow, edited by E. Mycielska-Dowgiallo, J. Rutkowski (Uniwersytet Warszawski, 1995)

8. PN-88/B-04481:1988. Grunty budowlane. Badania probek gruntu. (Polski Komitet Normalizacyjny, Warszawa, 1998)

9. PN-ISO 565: 2000. Sita kontrolne. Tkanina $z$ drutu, blacha perforowana $i$ blacha cienka perforowana elektrochemicznie. Wymiary nominalne oczek (Polski Komitet Normalizacyjny, Warszawa, 2000)

10. PN-EN 12620: 2004 Kruszywa do betonu (Polski Komitet Normalizacyjny, Warszawa, 2004)

11. PN-EN ISO 14688-2: 2006. Badania geotechniczne. Oznaczanie i klasyfikowanie gruntów. Czesc 2: Zasady klasyfikowania (Polski Komitet Normalizacyjny, Warszawa, 2006) 